\title{
Use of biochar obtained from coffee grounds as adsorbent of dyes and solid biofuel
}

\author{
Monique Kort-Kamp Figueiredo ${ }^{1}$, Karolyne Nogueira de Castro Caldas², Beatriz Pereira do \\ Nascimento $^{3}$, Priscila Schroeder ${ }^{4}$, Gilberto Alves Romeiro ${ }^{5}$ \\ ${ }^{1}$ Professor of Federal Institute of Education, Science and Technology of Rio de Janeiro - IFRJ, Campus Duque de Caxias, RJ, \\ Multidisciplinary Laboratory of Waste Management - LMGR \\ 2,3Student of Federal Institute of Education, Science and Technology of Rio de Janeiro - IFRJ, Campus Duque de Caxias, RJ \\ ${ }^{4}$ Doctoral Student of Federal Fluminense University - UFF, Chemistry Laboratory - LABCON. \\ ${ }^{5}$ Professor of Federal Fluminense University - UFF, Chemistry Laboratory - LABCON. \\ monique.figueiredo@ifrj.edu.br.
}

\begin{abstract}
Brazil is the world's largest coffee producer and the second largest consumer. In 2016, the coffee crop was one of the largest in the country's history. One of the main residues of the coffee industry is coffee grounds. They are a daily waste in almost all residences, shops, bars and restaurants. The high production ends up generating an accumulation of waste due to the low processing capacity of this material. Thus, this work had the objective of finding alternative uses for this waste, to add value through the production of solid biofuel and activated biochar to remove contaminants. These bioproducts, as well as being good alternatives to minimize production waste, reduce the use of petroleum and consequently emissions of greenhouse gases. Biochar was obtained by slow pyrolysis of coffee grounds. In order to evaluate the the fuel capacity, characterization was carried out through physical-chemical analyses to measure moisture, ash, volatile material and fixed carbon contents, and elemental analysis to determine theoretical calorific value. The activated biochar was also tested as an adsorbent of organic dyes.
\end{abstract}

Keywords: biochar, adsorbent, coffee grounds, solid biofuel.

\section{Introduction}

Growing interest is devoted to the possibility of producing new renewable alternative fuels and their significant participation in the energy mix, due mainly to the wide range of waste discarded on a daily basis and the need to reduce the use of petroleum products and consequently the energy dependence of countries. In addition, reducing the consumption of petroleum products also decreases the emission of gases, responsible for global warming (FIGUEIREDO, 2008; INNOVA, 2016).

Biomass energy is that provided by materials of renewable plant origin. Brazil has been developing technology for many years to use biomass as a source of energy, generating jobs with scarce financial resources. Today there are several renewable sources of biomass, especially sugarcane to 
produce ethanol, in which Brazil is the global leader. However, another potential source of plentiful biomass in the country is coffee grounds (FIGUEIREDO, 2008).

Coffee is native to Ethiopia in central Africa, and spread to the rest of the world through Arabia and later by European colonizers of the Americas. It was brought to Brazil in 1727, where it was first cultivated in Belém, in the state of Pará. Due to favorable climatic conditions, coffee cultivation spread rapidly, becoming in a relatively short time the main product of the Brazilian economy. Brazil is still the world's largest producer of coffee.

According to data from CONAB (the government's agricultural supply agency), Brazilian coffee production from the 2016 crop reached 51.37 million bags $(60 \mathrm{~kg})$ of processed beans. This was the second highest harvest in history, behind only the 2002 harvest (50.8 million bags). This production was $18.8 \%$ higher than the 43.24 million bags obtained in 2015. Among the agricultural products exported by Brazil, coffee occupied fifth position in 2016, bringing US\$ 5.47 billion in foreign exchange (CAVALCANTE, 2016; MINISTÉRIO da AGRICULTURA, PECUÁRIA e ABASTECIMENTO, 2017).

Industrial production of soluble coffee generates coffee grounds. According to NBR 10004 (Brazilian Association of Technical Standards, 1987), these residues are classified as class II non-inert waste, which are solid wastes that are water soluble and can also be biodegradable and combustible. It is estimated that for each ton of soluble coffee produced, 4.5 tons of coffee grounds are generated (CONSÓRCIO PESQUISA CAFÉ, 2016). Coffee grounds are also a daily waste in almost all residences, shops, bars and restaurants, and are generally discarded as rubbish. Although not oleaginous, they contain a certain percentage of saturated and unsaturated fatty acids, thus making them potential sources of organic substances after soft pyrolysis.

This article contributes by examining the pyrolysis of the coffee grounds to produce fuel and to treat wastewater. Pyrolysis is thermal decomposition in the absence of oxygen. It is the first stage of combustion and gasification processes. Biomass pyrolysis produces gas, liquid and solid. The gas is composed of carbon monoxide, carbon dioxide and light hydrocarbons. The dark colored liquid is called bio-oil and the lighter liquid is classified as oily water. The solid material is biochar. Pyrolysis receives different denominations depending on the conditions used. In this work, we used slow pyrolysis, involving low temperatures and long residence times (FIGUEIREDO, 2008; SANTOS, 2011; SILVA, 2014).

The solid fraction consists mainly of char and ash (depending on the temperature employed). These substances can be used as solid fuel with high colorific power or in the manufacture of activated charcoal, for filtration to eliminate impurities from certain substances through chemical interaction (PICOLLA, 2013).

\section{Methodology}

\subsection{Samples}

The coffee grounds used in this project were collected in the residences of the participants.

\subsection{Pyrolysis}

The conversions were carried out in a batch reactor, consisting of a Heraus R / O 100 furnace, a temperature controller, operating timer, fixed bed consisting of boron-silicate glass with dimensions $1.40 \mathrm{~cm} \times 10 \mathrm{~mm}$, a liquid collection system consisting of a condenser, a settling funnel and three flushing flasks. This system was already in operation in the Low Temperature Conversion Laboratory (LABCON) (Figueiredo, 2008). 


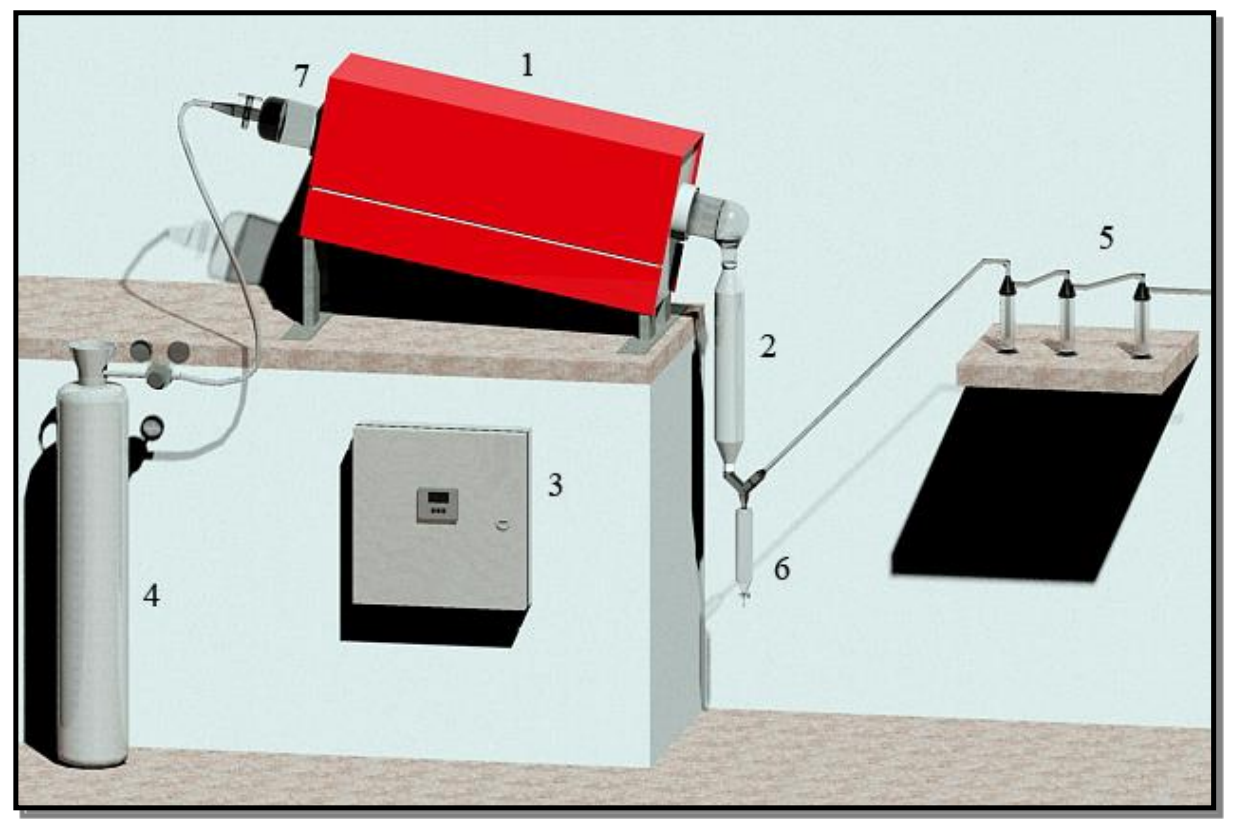

Figure 1 - Pyrolysis reactor and components (1-reactor, 2-condenser, 3-temperature controller, 4-gas cylinder, 5-gas flushing vials, 6-liquid collector and 7-borosilicate bed.

The conversions were carried out in a bench reactor in batch process, with the absence of oxygen at a temperature of $400{ }^{\circ} \mathrm{C}$ for 2 hours. After that time, the charcoal remained in the reactor until it cooled and then was evaluated for its physicochemical characteristics.

\subsection{Granulometric classification of biochar}

The biochar obtained in the pyrolysis process was macerated in a mortar and sieved to attain granulometry from 0.045 to $0.212 \mathrm{~mm}$.

\subsection{Determination of moisture content of biochar}

The biochar was oven dried at $105 \pm 2{ }^{\circ} \mathrm{C}$. The moisture content is the percentage calculated from the difference between the initial mass without heating and the final mass after heating to constant mass, based on the NBR-8293/1983 standard.

\subsection{Volatile matter content}

The volatile matterl content of coffee grounds and biochar was determined as described in the NBR 8290, 1983 standard.

\subsection{Fixed carbon content}

According to ABNT NBR 8299/1983, the fixed carbon content of a solid is calculated from the ash, volatile matter and moisture contents, according to the following equation:

Fixed carbon $=100-(\%$ moisture $+\%$ ash + volatile matter $)$

\subsection{Elemental analysis}

The total determination of carbon, hydrogen and nitrogen in the coffee grounds and biochar was performed with a Perkin Elmer II CHN analyzer, with the reference standard acetanelide (C = 
$71.09 \%, \mathrm{H}=6.71 \%, \mathrm{~N}=10.36 \%$ ). The mean analytical accuracy was $\pm 0.1 \%$ for $\mathrm{CT}$ and $\pm 0.06 \%$ for $\mathrm{H}$ and NT. For both samples, the oxygen content was calculated by difference.

\subsection{Higher heating power}

The higher calorific value (HCV) was calculated according to the equation described in the work of Demirbas (1997):

$$
H C V\left(\frac{M j}{K g}\right)=(0.335 \times \mathrm{C})+(1.423 \times \mathrm{H})-(0.154 \times 0)-(0.145 \times \mathrm{N})
$$

\subsection{Treatment of biochar}

Treatment steps were as follows:

$\checkmark$ Separation of biochar fractions in different granulometry, making the particles that constitute it and their distribution more uniform.

Soxhlet extraction, minimizing remaining oil quantities in the biochar with the use of solvents with different polarities, such as hexane, dichloromethane and methanol.

$\checkmark$ Activation of biochar with sulfuric acid, causing the pores to expand and increase their adsorptive potential.

\subsubsection{Biochar activation method}

In a $125 \mathrm{~mL}$ flask, $20 \mathrm{~g}$ of biochar and $20 \mathrm{~mL}$ of concentrated $\mathrm{H}_{2} \mathrm{SO}_{4}$ were mixed and then heated at $200{ }^{\circ} \mathrm{C}$ for 1 hour in a silicone bath. During the activation, stirring was initiated, the water was evaporated and the mixture became a slurry and began to solidify. At this point, the stirring was stopped while the heating continued. Traces of Milli-Q water were injected into the material using a 10 $\mathrm{mL}$ syringe to promote activation.

The mixture was then cooled to room temperature, washed with Milli-Q water and soaked in a $10 \% \mathrm{NaOH}$ solution $(\mathrm{m} / \mathrm{v}$ ) for 30 minutes to neutralize the surface, and re-washed with Milli-Q water until the water reached neutral $\mathrm{pH}$, dried in an oven at $105^{\circ} \mathrm{C}$ and stored in a desiccator.

\subsection{Adsorption of biochar}

Part I- Preparation of solutions: Prepare solutions with different concentrations (0.5, 1.0, 2.5, 5.0, $7.5,10.0,12.5,15.0,17.5,20.0 \mathrm{~g} / \mathrm{L}$ ) with the adsorbate solution (methylene blue and malachite green) from the stock solution $(250 \mathrm{~g} / \mathrm{L})$ in volumetric flasks $(100 \mathrm{ml})$.

$(10 \mathrm{ml})$.

Part II- System preparation: material; stir bar, magnetic bar, beakers (10 and $50 \mathrm{ml})$ and pipette

Part III - Wash all beakers and the pipette mainly with alcohol and let them dry completely before use. With the cooled beakers, weigh $10 \mathrm{mg}$ of biochar $(0.01 \mathrm{~g})$ on an analytic balance. Then use the pipette to add $10 \mathrm{ml}$ of the solutions. Shake the solution for 1 hour, filter it and transfer it to the test tube for analysis. 
Part IV- Plot a calibration curve with the standard solutions and then analyze the samples to discover their concentrations and finally use the following equation to determine the amount of methylene blue in each sample.

$$
\begin{aligned}
& Q=(\text { Co-Cf }) . V / m \\
& Q=\text { amount of methylene blue } \\
& C o=\text { initial concentration } \\
& C f=\text { final concentration } \\
& V=\text { volume of methylene blue } \\
& M=\text { mass of biochar. }
\end{aligned}
$$

\subsection{Statistical analysis}

The Scott-Knott test (Scott and Knott, 1974) was used to analyze the statistical significance of the pyrolysis results between the triplicates. The same was used to test for significant differences between the triplicates results. All calculations in this work were performed by Assistat 7.7(Silva and Azevedo, 2016).

\section{Results and discussion}

According to NBR 10.004 Solid waste - Classification (ABNT, 2004), this coffee waste is classified as: Class II A, Not Hazardous - Not Inert.

Through the pyrolysis of the coffee grounds it was possible to acquire the main products of the process. The percentage yields obtained are presented in Table 1.

Table 1: Yields obtained in the pyrolysis process of the coffee grounds

\begin{tabular}{ccccc}
\hline Yields (\%) & Bio-oil & Aqueous fraction & Biochar & Gas Fraction \\
\hline 1 & $21.0 \mathrm{a}$ & $28.5 \mathrm{a}$ & $33.0 \mathrm{a}$ & $18.0 \mathrm{a}$ \\
2 & $19.5 \mathrm{~b}$ & $43.0 \mathrm{~b}$ & $32.0 \mathrm{a}$ & $5.5 \mathrm{~b}$ \\
3 & $18.5 \mathrm{~b}$ & $29.5 \mathrm{a}$ & $33.5 \mathrm{a}$ & $18.5 \mathrm{a}$ \\
4 & $16.0 \mathrm{c}$ & $23.0 \mathrm{~d}$ & $37.5 \mathrm{~b}$ & $23.5 \mathrm{c}$ \\
5 & $16.0 \mathrm{c}$ & $27.3 \mathrm{c}$ & $34.0 \mathrm{a}$ & $22.7 \mathrm{c}$
\end{tabular}

* Evaluation of the percentage yields for the pyrolysis procedures. The average values followed by the same lowercase letter in the column do not differ statistically from each other by Scott-Knott test $(\mathrm{p}<0.01)$.

The average values of the five pyrolysis procedures are shown in Table 2. For the procedure with bio-oil the best yield was found in the first pyrolysis (21.0\%). Procedure five presented the worst yield $(16.0 \%)$. Additionally, for the aqueous fraction the best yield was found in the second procedure $(43.0 \%)$ and the worst yield $(23.0 \%)$ in the fourth procedure. For the biochar fraction, the best yield was found in the fourth procedure (37.5\%) and the worst yield (33.0\%) in the first procedure. Finally, for gas fraction, the best yield was obtained with the fourth procedure $(23.5 \%)$ and the worst $(5.5 \%)$ with the second procedure. These variations may have occurred due to the way the residue was placed in the converter tube, the variation in the quantity inserted, and the moisture content of the raw material. Also, during the conversion, a small leak in the system was detected, causing greater yield of the gas phase in the fourth and fifth procedures. Another possible cause for the difference in yields is the separation of the liquid phases into bio-oil and aqueous phases, because varying times it took to separate the phases may have led to a greater or lesser emulsification or solubilization of the phases.

\subsection{Elemental analysis of coffee grounds and biochar and calculation of calorific value:}

The percentages found for carbon, hydrogen, nitrogen and oxygen in coffee grounds and biochar are presented in Table 2. 
Table 2: Elemental analysis of coffee grounds

\begin{tabular}{ccccc}
\hline & $\begin{array}{c}\text { Carbon } \\
( \pm 0.1) \%\end{array}$ & $\begin{array}{c}\text { Hydrogen } \\
\pm 0.06) \%\end{array}$ & $\begin{array}{c}\text { Nitrogen } \\
( \pm 0.06) \%\end{array}$ & $\begin{array}{c}\text { Oxygen\% } \\
( \pm 0.39)\end{array}$ \\
\hline Coffee grounds & 54.82 & 6.05 & 1.93 & 36.03 \\
Biochar & 80.70 & 4.38 & 3.32 & 7.74 \\
\hline
\end{tabular}

The oxygen content was calculated by difference. Through the values obtained by the elemental analysis of the material it was possible to calculate the calorific value of $21.15 \mathrm{MJ} / \mathrm{kg}$ for the coffee grounds. For the biochar the calorific value was $31.59 \mathrm{MJ} / \mathrm{kg}$.

The values found in the elemental analysis are in agreement with those expected for a biomass and charcoal. There was a considerable increase in the calorific value of the biomass for the biochar. This shows that the pyrolysis technique can be a good alternative to obtain charcoal for use as a solid fuel.

\subsection{Biochar moisture content}

The moisture contents determined for the biochar in different particle sizes are shown in Table 3.

Table 3. Determination of the moisture content of biochar. The average values followed by the same lowercase letter do not differ statistically from each other by the Scott-Knott test $(p<0.05)$.

\begin{tabular}{cccc}
\hline \multirow{2}{*}{ Sample } & \multicolumn{3}{c}{ Particle size } \\
& Gross & $<0.045 \mathrm{~mm}$ & $0.045<\mathrm{C}<0.212 \mathrm{~mm}$ \\
\hline 1 & 2.28 & 4.39 & 4.71 \\
2 & 2.44 & 4.33 & 4.59 \\
3 & 2.26 & 3.83 & 4.34 \\
4 & 2.67 & 3.85 & 4.16 \\
5 & 3.05 & 4.61 & 4.53 \\
\hline Average & $2.54 \mathrm{~b}$ & $4.20 \mathrm{a}$ & $4.47 \mathrm{a}$ \\
\hline Standard Deviation & 0.329 & 0.347 & 0.217 \\
\hline
\end{tabular}

The low values obtained for the moisture content of the biochar show that it can be used as a solid fuel or as an adsorbent of impurities. The higher the moisture content, the lower will be the ability to remove impurities and the greater the need for energy for combustion.

The Scott-Knott test at 5\% probability level showed there was no statistical difference between the average particle sizes of $0.045<\mathrm{C}<0.212 \mathrm{~mm}$ and $<0.045 \mathrm{~mm}$.

\subsection{Ash content}

The average ash content of the coffee grounds was $1.17 \%$ with a standard deviation of 0.1458 .

Table 4 shows the values obtained for the ash content of the biochar with different granulometry. The ash content is an important parameter for solid fuels because it is necessary to know how much residue will remain after combustion of the material.

The Scott-Knott test at 5\% probability level shows no statistical difference between the averages for the samples. 
Table 4: Determination of ash content of biochar. The average values followed by the same lowercase letter do not differ statistically from each other by the Scott-Knott test $(\mathrm{p}<0.05)$.

\begin{tabular}{cccc}
\hline Sample & \multicolumn{3}{c}{ Particle size } \\
& Gross & $<0.045 \mathrm{~mm}$ & $0.045<\mathrm{C}<0.212 \mathrm{~mm}$ \\
\hline 1 & 3.07 & 3.98 & 3.56 \\
2 & $4, .09$ & 4.13 & 3.72 \\
3 & 4.05 & 4.07 & 4.30 \\
\hline Average & $3.74 \mathrm{a}$ & $4.06 \mathrm{a}$ & $3.86 \mathrm{a}$ \\
\hline Standard Deviation & 0.581 & 0.078 & 0.392 \\
\hline
\end{tabular}

\subsection{Volatile material content}

Another important parameter for solid fuels is the volatile material content. Volatile materials are defined as substances that are released from char as gases during burning. The factors influencing the volatile materials are the carbonization temperature, heating rate and chemical composition of the biomass.

The coffee grounds had a mean volatile content of $85.74 \%$ with a standard deviation of 0.281 .

For the biochar, the results of the volatile content are presented in Table 5.

The Scott-Knott test at $5 \%$ probability level shows no statistical difference between the averages for the particle sizes of $0.045<\mathrm{C}<0.212 \mathrm{~mm}$ and $<0.045 \mathrm{~mm}$.

Table 5: Determination of the content of volatile biochar. The average values followed by the same lowercase letter do not differ statistically from each other by the Scott-Knott test $(\mathrm{p}<0.05)$.

\begin{tabular}{cccc}
\hline Sample & \multicolumn{3}{c}{ Particle size } \\
& Gross & $<0.045 \mathrm{~mm}$ & $0.045<\mathrm{C}<0.212 \mathrm{~mm}$ \\
\hline 1 & 26.98 & 35.86 & 35.42 \\
2 & 25.43 & 35.80 & 35.50 \\
3 & 26.19 & 35.90 & 35.45 \\
\hline Average & $26.20 \mathrm{~b}$ & $35.85 \mathrm{a}$ & $35.46 \mathrm{a}$ \\
\hline Standard Deviation & 0.774 & 0.050 & 0.037 \\
\hline
\end{tabular}

\subsection{Fixed carbon content}

After analysis of the moisture, ash and volatile material, it was possible to calculate the fixed carbon content for the biochar with different granulometries. The fixed carbon content was calculated from the averages of the values of these analyses and the results are presented in Table 7.

Table 6: Determination of the content of fixed carbon

\begin{tabular}{cccc}
\hline Sample & \multicolumn{3}{c}{ Particle size } \\
& Gross & $<0.045 \mathrm{~mm}$ & $0.045<\mathrm{C}<0.212 \mathrm{~mm}$ \\
\hline Average & 67.52 & 55.89 & 56.22 \\
\hline Standard Deviation & 1.022 & 0,359 & 0,449 \\
\hline
\end{tabular}


Fixed carbon is directly related to calorific value: the higher the fixed carbon value is, the longer the residence time of the fuel in the combustion chamber will be. The biochar had good fixed carbon content, as well high calorific power, so it can be used as solid fuel.

\subsection{Removal of the dyes using neutral activated biochar}

The biochar was tested as an adsorbent of impurities by evaluating its ability to remove organic dyes.

The calibration curve was first plotted for the methylene blue dye using 16 points. The equation obtained was used to calculate the concentrations of the solutions after adsorption. The calibration curve used is shown in Figure 2.

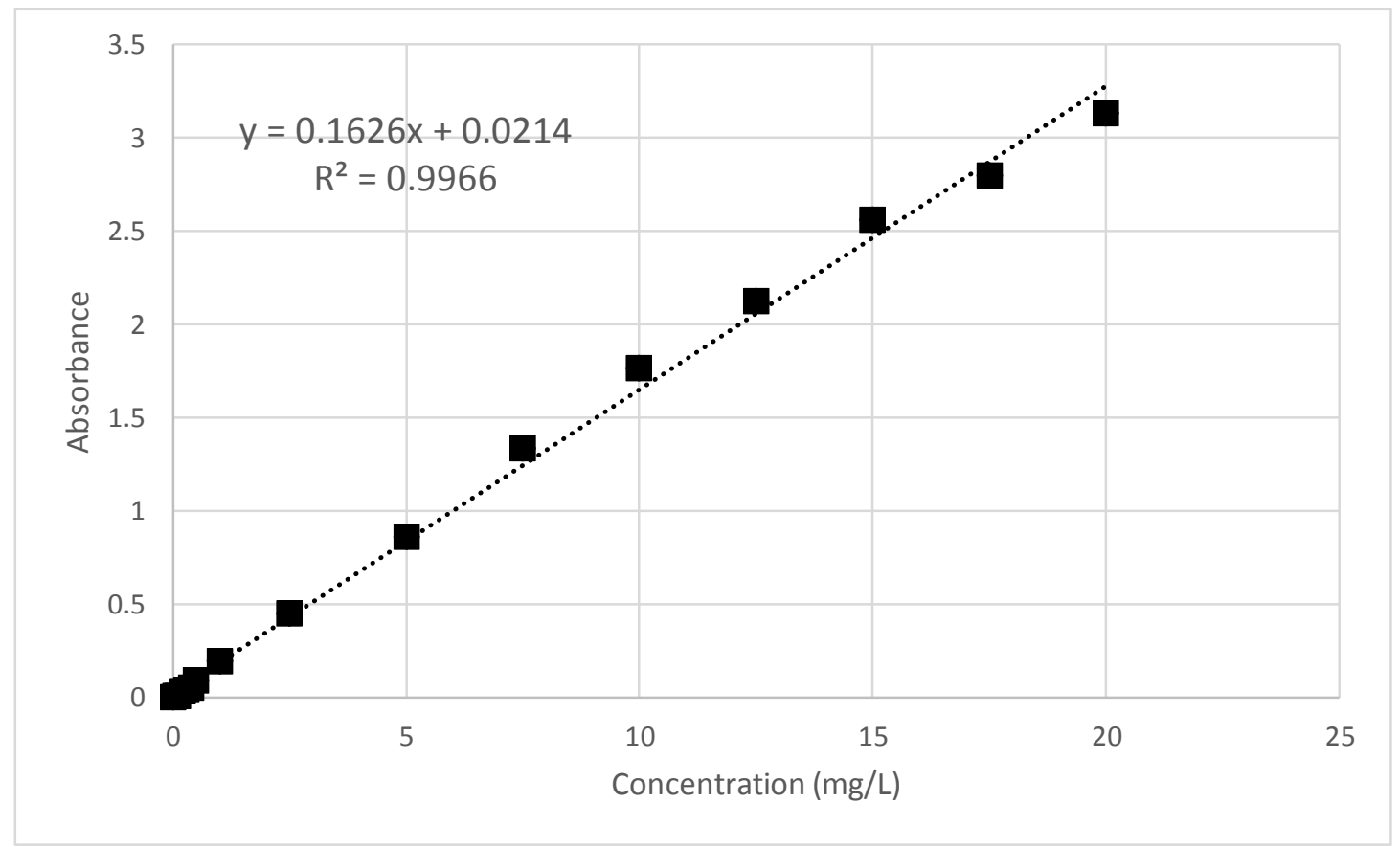

Figure 2: Calibration curve obtained for the methylene blue dyes.

Activated biochar was then tested as an adsorbent of methylene blue solutions and the results obtained for the neutral activated biochar with $0.212 \mathrm{~mm}$ particle size are shown in Table 7.

Table 7: Removal of methylene blue with the neutral activated biochar $(0.212 \mathrm{~mm})$. The average values followed by the same lowercase letter do not differ statistically from each other by the Scott-Knott test $(\mathrm{p}<0.05)$.

\begin{tabular}{cccc}
\hline Initial Concentration $(\mathrm{mg} / \mathrm{L})$ & Final Concentration $(\mathrm{mg} / \mathrm{L})$ & Removal $(\mathrm{mg} / \mathrm{L})$ & $\%$ Removal \\
\hline 0.5 & $0.07 \mathrm{a}$ & 0.43 & 86.22 \\
1.0 & $0.06 \mathrm{a}$ & 0.94 & 93.57 \\
2.5 & $0.01 \mathrm{a}$ & 2.49 & 99.61 \\
5.0 & $0.01 \mathrm{a}$ & 4.99 & 99.79 \\
7.5 & $0.06 \mathrm{a}$ & 7.44 & 99.17 \\
10.0 & $0.09 \mathrm{a}$ & 9.91 & 99.12 \\
12.5 & $0.11 \mathrm{a}$ & 12.39 & 99.14 \\
15.0 & $0.19 \mathrm{a}$ & 14.81 & 98.76 \\
17.5 & $0.15 \mathrm{a}$ & 17.35 & 99.15 \\
20.0 & $0.06 \mathrm{a}$ & 19.94 & 99.68 \\
\hline
\end{tabular}


The Scott-Knot test at 5\% probability showed no statistical difference between the average final concentrations of the analyzed solutions. This result shows that the biochar is capable of adsorbing the analyte at all concentrations analyzed without losing its ability to remove the dye.

Figure 3 shows the curve of the initial solution (circle symbol) and the curve of the solution after removal of the dye using the activated neutral biochar (triangle symbol). We can observe that there is a great reduction in the curve of the solution after removal (triangle symbol), which represents the removal of the dye by the activated biochar. The graph of Figure 3 indicates that the activated biochar was very efficient in removing the methylene blue dye.

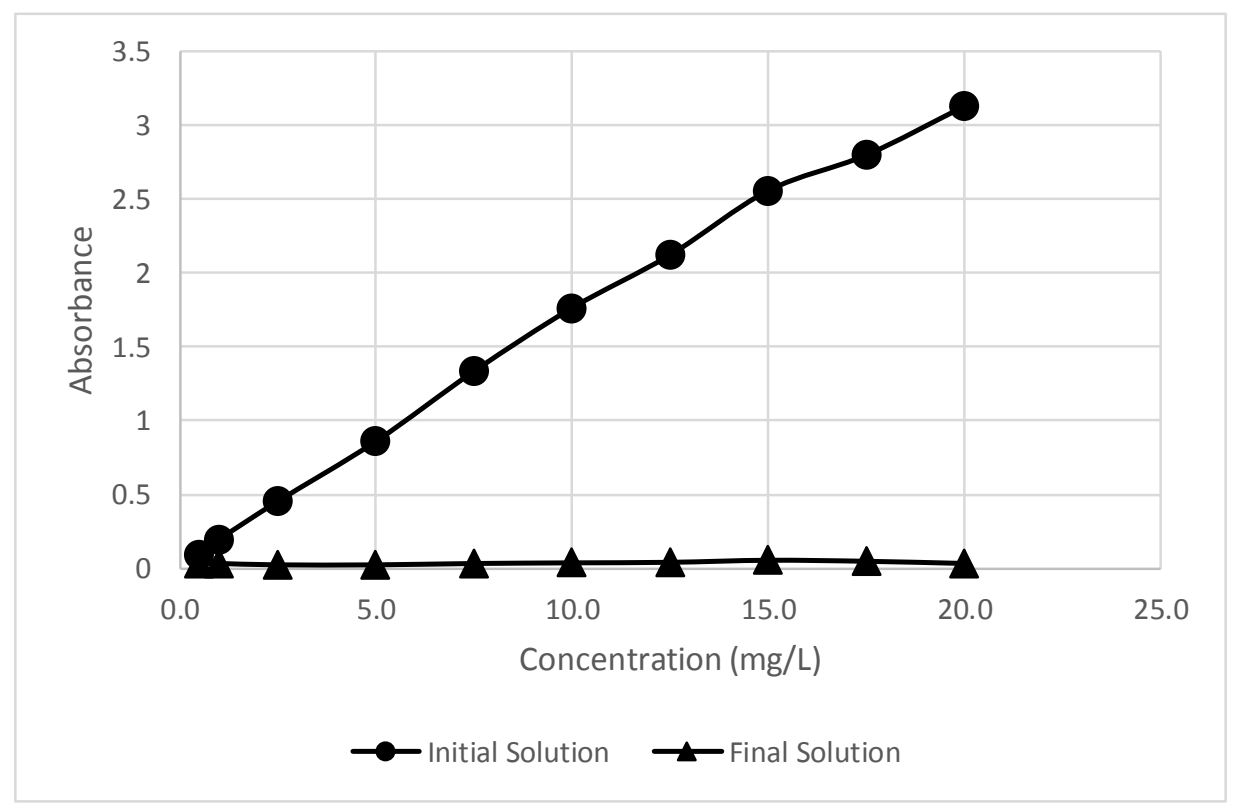

Figure 3-Curves of the initial solution compared to the curve of the final solution after removal of the dye with neutral activated biochar.

The calibration curve for the malachite green dye is shown in Figure 4. Seven points were used to obtain the curve and the equation obtained was used to calculate the concentrations of the solutions after adsorption.

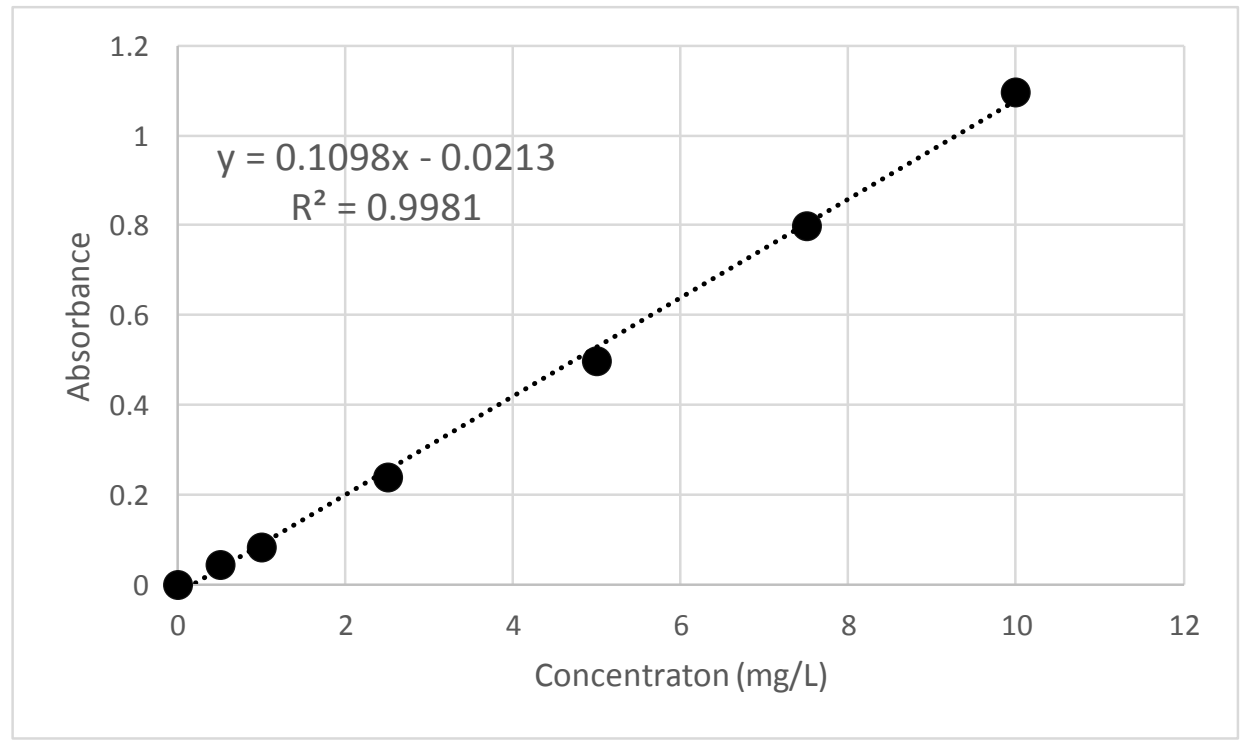

Figure 4: Calibration curve obtained for the malachite green dye. 
Activated biochar was then tested as an adsorbent of malachite green solutions and the results obtained for the neutral activated biochar with $0.212 \mathrm{~mm}$ particle size are shown in Table 8 .

Table 8: Removal of the malachite green dye with the neutral activated biochar $(0.212 \mathrm{~mm})$. The average values followed by the same lowercase letter do not differ statistically from each other by the Scott-Knott test $(\mathrm{p}<0.05)$.

\begin{tabular}{cccc}
\hline Initial Concentration $(\mathrm{mg} / \mathrm{L})$ & Final Concentration $(\mathrm{mg} / \mathrm{L})$ & Removal $(\mathrm{mg} / \mathrm{L})$ & \%Removal \\
\hline 0.5 & $0.43 \mathrm{~d}$ & 0.07 & 13.24 \\
1.0 & $0.44 \mathrm{~d}$ & 0.56 & 55.71 \\
2.5 & $0.38 \mathrm{~d}$ & 2.12 & 84.95 \\
5.0 & $0.46 \mathrm{~d}$ & 4.54 & 90.84 \\
7.5 & $0.56 \mathrm{c}$ & 6.94 & 92.56 \\
10.0 & $0.52 \mathrm{c}$ & 9.48 & 94.75 \\
12.5 & $0.62 \mathrm{~b}$ & 11.88 & 95.07 \\
15.0 & $0.65 \mathrm{~b}$ & 14.35 & 95.67 \\
17.5 & $0.72 \mathrm{~b}$ & 16.78 & 95.89 \\
20.0 & $0.90 \mathrm{a}$ & 19.10 & 95.48 \\
\hline
\end{tabular}

The Scott-Knott test at 5\% probability shows a significant difference between the means of the final concentrations after removal of the dye in the solutions with concentrations higher than 7.5 $\mathrm{mg} / \mathrm{L}$. This result indicates there is a limitation on the ability of the activated biochar to remove malachite green dye. At high concentrations, the activated biochar begins to remove the dye less efficiently than at the lower concentrations. Despite this limitation, the activated biochar is still very efficient for removal of malachite green dye.

Figure 5 shows the curve of the initial malachite green solutions (square symbol) and the curve of malachite green solutions after treatment with the activated biochar (rhombus symbol). The dye removal was very efficient because a large reduction occurred in of the initial solutions in comparison to the curve of malachite green solutions after treatment with the activated biochar (rhombus symbol).

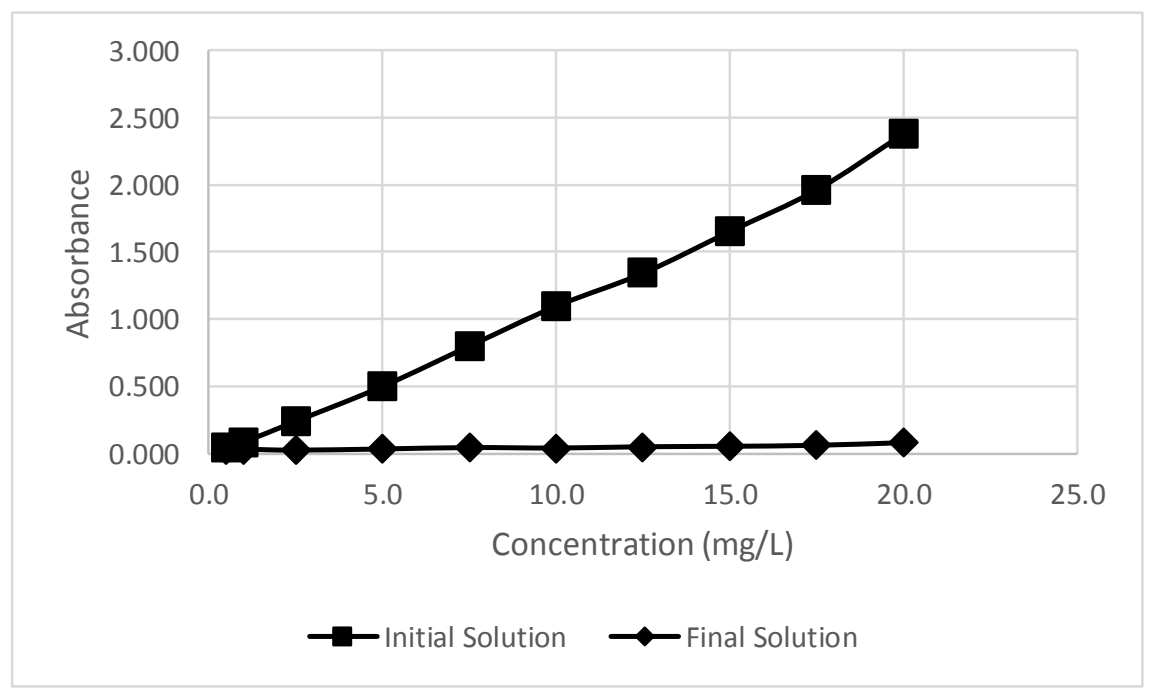

Figure 5: Curves of the initial solution compared to the curve of the final solution after removal of the malachite green dye with activated biochar.

By observing the results obtained in the adsorption tests, it can be concluded that the activated biochar has good potential for sue as an adsorbent of organic dyes. 


\section{Conclusions}

Agro-industrial waste is often used to generate energy or for irrigation or fertilization of crops. The products obtained by pyrolysis can be used either as a fuel by direct burning or for filtration of wastewaters, with twofold benefits: reduction of costs and reduction of environmental pollution.

The slow pyrolysis at $400{ }^{\circ} \mathrm{C}$ showed good distribution in product yields. The biochar was obtained with $34 \%$ yield with good characteristics both for use as a solid fuel and for adsorption as activated charcoal. Bio-oil yield was $18.2 \%$ and the aqueous fraction presented $28.9 \%$ yield, with possible agro-industrial applications. The gas presented $17.64 \%$ yield and can be reused in the generation of energy to feed the pyrolysis process itself, making it a very viable alternative to waste disposal.

The results of the adsorption tests indicate that the activated biochar obtained from the coffee grounds has high adsorption power, reaching a 99.79\%, making it a promising adsorbent for the removal of organic dyes from industrial waste.

Another important application for biochar is as alternative solid fuel. The results showed that the biochar has strong potential for use as a fuel, with calorific value of $31.59 \mathrm{MJ} / \mathrm{kg}$, much higher than the original biomass of $21.15 \mathrm{MJ} / \mathrm{kg}$. In addition, it had low ash content and low moisture.

For this reason, pyrolysis is an important technique to obtain biofuels, which can help reduce oil dependence and minimize environmental problems.

\section{Acknowledgments}

We are grateful for the PIBITI Jr. scholarship granted by IFRJ, and to CNPq, CAPES and FAPERJ for financial support.

\section{References}

ABIC (Associação Brasileira da Indústria de Café) (2016). Estatística do Consumo Interno. Available at: URL http://www.abic.com.br. Consulted on: February 20, 2016.

CAVALCANTE, T.; (2016) Safra de café em 2016 deve ser a segunda maior da história, estima Conab. Agência Brasil, 20/01/2016. Available at: URL http://agenciabrasil.ebc.com.br/economia/noticia/2016-01/safra-de-cafe-em-2016-deve-ser-segundamaior-da-historia-estima-conab. Consulted on: June 26, 2016.

CONSÓRCIO PESQUISA CAFÉ. (2016) Informe Estatístico do Café. Available at: URL http://www.consorciopesquisacafe.com.br e www.embrapa.br/cafe. Consulted on: February 21, 2016.

DEMIRBAS, (1997) A. Calculation of higher heating values of biomass fuels. Fuel, v. 76, n. 5, p. 431-434.

FIGUEIREDO, M.K-K.(2008) Mamona como insumo na produção de combustíveis alternativos obtidos em processo de conversão a baixa temperatura (CBT). Dissertação (mestrado) - Universidade Federal Fluminense.

INNOVA: Energias Renováveis - Biomassa Residual. (2016) Available at: http://www.innovabr.com. Consulted on: February 23, 2016.

MINISTÉRIO DA AGRICULTURA, PECUÁRIA E ABASTECIMENTO, Café no Brasil, 10/03/2017. Available at: http://www.agricultura.gov.br/assuntos/politica-agricola/cafe/cafeicultura-brasileira. Consulted on: October 2, 2017. 
PICOLLA, C.D. (2013) Características químicas de biocarvões produzidos a partir do bagaço de canade- açúcar e a disponibilidade de fósforo no solo. (Dissertação mestrado) - Universidade de São Paulo.

SANTOS, K.G. (2011) Aspectos fundamentais da pirólise de biomassa em leito de jorro: fluidodinâmica e cinética do processo. (Tese de doutorado) - Universidade Federal de Uberlândia.

SCOTT, A. J.; KNOTT, M. A. (1974) A Cluster analysis method for grouping means in the analysis of variance. Biometrics. Raleigh, v.30, n.3, p. 507-512. Sept.

SILVA, F. de A. S. and.; AZEVEDO, C. A. V. DE. (2016) The Assistant Software Version 7.7. and its use in the analusis of experimental data. Afr. J. Adric. Res, v.11, n.39, p.3733-3740.

SILVA, R. V. da. (2014) Pirólise da Torta de Mamona como uma opção de destino para este resíduo. 2014. 146 páginas. (Tese de Doutorado). UFF. Niterói, RJ. February 2014. 